\title{
IV
}

\section{As condições existenciaes das lesões deformatorias}

22.) - No capitulo anterior, dissemos que deformar é, em ultima analyse, afear: essa é, com effeito, a substancia das lesões deformatorias.

Resta-nos precisar os contornos, accentuar as linhas, analysar as condições existenciaes da deformidade perante a lei penal.

E' obvio que sómente nos occuparemos dos elementos caracteristicos das lesões dessa natureza.

23.) - $O$ art. 304 do codigo de $\mathrm{I} 890 \mathrm{diz}$ concisamente: «se da lesão corporal resultar deformidade....»

Não restringe a amplitude da expressão,- - ou estabelecendo graus de damno esthetico, a exemplo dos codigos italiano, venezuelano e portuguez,_-ou exigindo a concurrencia de requisitos de duração, intensidade, visibilidade e situação dos vestigios do traumatismo, como os codigos italiano (sfregio permanente del viso, art. 372, г. ${ }^{\circ}$, permanente deformazione del viso, art. 372 , 2. ), uruguayo (deformación permanente del rostro) chileno (notablemente deforme, art. 394, § $1.0^{\circ}$ ), argentino (notablemente deforme, art. i I $9, \S 33^{\circ}$ ), hespa- 
nhol, de i 850 (notablemente deforme, art. 343) (I), finlandez (deformidades graves, c. $2 \mathrm{I}, \S 5$ ), austriaco (deformidade notavel, art. I 56, a), (2), venezuelano (cicatriz notable de la cara, art. $379, \S 1 .^{\circ}$, herida que desfigure á la persona, $\S 2 .^{\circ}$ ), sardo, (deturpato permanentemente la faccia, art: 538 , III), toscano (deturpa la faccia, art. 326 , II, c), de Thurgovia (desfigurado ostensivamente, art. 85) (3), de Lucerna (deformidade importante), de Grisons (desfiguração notavel), de Friburgo (deformidade ou desfiguração, art. 144), da India Ingleza (desfiguração permanente), o codigo hungaro (desfigurar de modo apparente, § 303) (4), o allemão (deformar velezante e permanentemente, § 224) (5), os projectos austriaco (desfigurado para sempre, art. 236), russo (deformação da face), e brasileiro (cicatriz temporaria no rosto, art. $299, \S 2 .^{\circ}, f$, deformidade permanente do rosto, art. 299, $\S 33^{\circ}, f$ ), e o ante-projecto do codigo suisso (desfigurar completamente uma pessoa, art. 6I) (6).

Do extremo laconismo do codigo, preconisado, aliás, por De Crecchio, Rivarola e Carrara, promanam a incerteza das hypotheses na doutrina, a vacillação dos arestos nos tribunaes. Bem se comprehende que a disposição legal não destrince detalhes. No entretanto, seria talvez preferivel que, relativamente a certas condições das lesões deformatorias, a lei, prolixa, mas terminantemente, dissesse o que atira ao azar das interpretações e á adevinhação de magistrados e peritos.

(I) R. Rivarola, Cód. Pen., II, p. $r 08$.

(2) Hofmann, Tratado, I, p. 3I 4. O art. 4 I I falla de signaes resultautes dos ferimentos. Diz tambem o codigo portuguez, de $185_{2}^{2}$, art. 360 : «toda a uffensa corporal voluntaria, que causar alguma ferida, ou contusão, ou soffrimento de que ficasse algum vestigio...

(3) Van Swinderen, Esquisse du droit pénal actuel, II, p. 83. Desse livro extrahimos o que se refere aos codigos suissos, á lei finlandeza, ao projecto do codigo russo e ao codigo da India Ingleza.

(4) Garraud, Traité de droit pénal français, I891, IV.

(5) Berner, Trattato di diritto penale, trad. Beriola, 1887 , p. 420.

(6) CH. Stooss, Avant-projet de code pénal, trad. Gautier, I894. 
Do art. 304 podemos dizer o que, sobre a parte correspondente do codigo hespanhol, escreve um de seus criticos: «cuanto más se estudian sus disposicio"nes, surjem em mayor número los problemas y se «acumulan sin medida las interrogaciones del ca«suismo» (I).

--São deformatorias sómente as lesões que affectam o rosto?

- A deformidade deve ser apparente?

-A deformidade deve ser irreparavel?

-A deformidade deve ser permanente?

Eis ahi varias interrogações que todos os dias se levantam: para respondel-as, o codigo não fornece um subsidio sequer. D'ahi-a necessidade de procurar na doutrina o que a lei occulta e a jurisprudencia não desvenda.

\section{4.)-A primeira condição refere-se á SÉDE DA DEFORMIDADE.}

Havemos por incontestavel que sómente produzem deformiclade, no sentido do art. 304 do codigo penal, as les̃̃es que têm por séde o rosto, ou que, situadas em ponto proximo, alteram as feições da face (2).

Dizem-n'o expressamente todas ou quasi todas as legislações antigas e varios codigos modernos, entre os quaes o sardo, o venezuelano, o italiano, o uruguayo, o das Indias Inglezas, o toscano, o projecto russo, o segundo projecto do codigo do Imperio (3), os pro-

(i) GaRcia y SoRIano, La reforma del codigo penal español, i 896,

(2) E' o que se dá muitas vezes com as lesões do pescoço.

(3) Art. 209: «Não se seguindo deformidade no rosto do ferido....» (T. ALves Junior, Annotações theoricas e praticas ao codigo criminal, III, I 883 , p. 29I). O primeiro projecto dizia, em sentido differente, no art. I46: «Se do mal corporeo resultar desfiguração, transformando-se o exterior da pessoa, de maneira que esta se torne menos agradavel. . 》 
jectos brasileiros (I); e não diversa é a tendencia dominante na jurisprudencia das nações cultas (2).

Especialmente na Italia, a intenção do legislador, neste ponto, manifestou-se inequivocamente. Os projectos de I 868 (art. 307, b), de I 870 (art. 34.0, b), de Vigliani (art. 372 ), do Senado (art. 379) referiam-se a una permanente deturpazione della faccia (3). Com o applauso de alguns'(4), a commissão revisora do projecto senatorial (1876) substituiu a palavra faccia pela palavra aspetto, de maior latitude, e o fez, sob proposta de Oliva, que ponderou serem egualmente damnosos os effeitos de uma cicatriz na face e os de uma cica-

(1) O projecto do codigo argentino, abraçando doutrina adversa, dizia:-«deformado en una parte del cuerpo." R. Rivarola, Cód. Pen., II, p. 108 .

(2) Em contrario pronuncia-se a jurisprudencia hespanbola, desde que os tribunaes entendem que a simples claudicação constitúe deformidade. 'E' evidente a confusão entre debilitaçã̃o de orgam e lesão deformadora (sentença de 31 de Outubro de 1895, na Revista general de legislación y jurisprudencia, parte relativa á jurisprudencia criminal, LV, p. I95).-Não menos digna de reparo e censura é uma outra sentença do mesmo Tribunal (2 de Junho de 1894) em que se diz que é deformidade «la hernia que ha quedado en el vientre» do offendido. A' mesma corrente deve obedecer a jurisprudencia austriaca pelo que diz HofmanN; ๑. c., I, p. 390. A jurisprudencia argentina interpreta muito diversamente o art. II $\$ 3 .^{\circ}$ do Codigo Penal, que nada refere sobre a séde das lesões. Tem entendido, com todo fundamento, que essa disposição não é applicavel «en el caso de que á la victima (mulher) le queden cicatrices en el cuello, nındificación en el timbre de la voz y entorpecimiento del cuello y de la mano»; e que «no implica deformación, una lesión que exije la amputación del pulgar de la mano izquierda». (MALAGARRIGA, o. c., p. I 49).

(3) «La stessa commissione aveva sostituito aspetto a faccia... per dare alla sanzione penale maggiore estensione. Non è però stato forse avvertito che la voce aspetto ba un significato soverchiamente esteso, onde potrebbe essere sconfinata l'interpretazione.》 Relazione ministeriale (ZANARDelli), citada por Impallomeni, no Trattato di diritto penale, de Cogliolo, II, parte $2 . .^{\mathrm{a}}$, p. 309 .

(4) DE CRECChIO, Sfregio e deformazione, no Giorn. di med.leg. I, p. 4 e seg.-Caprara, Lettera, no mesmo Giornale, p. 153 e seg.-R. GatTa, Compendio di medicina legale, I892, p. I40.-E. MAdiA, Compendio di med. leg., I896, p. I75.-No mesmo sentido, DE CAPITANi, Sfregio e deformazione, na Cassazione Unica, V, col. 32I, e ANnibale AlpI, Sfregio e deformazione, 1896 , p. 4 . 
triz no collo da mulher (I). Nenhuma daquellas expressões vingou; mas consignou-se motivadamente a repulsa da tendencia extensiva sustentada pela alludida commissão (2), tendencia que aliás predominára nos projectos Zanardelli, de 1883 (art. 327), Savelli (art. 332) e Pessina (art. 348).

Os scientistas partidarios da doutrina adversa limitam-se a formular uma aspiração irrealisada e a dirigir criticas ás leis que expressamente repudiam as suas ideas (3). Não vemos, porém, fundamentos infrangiveis em taes criticas e legitimidade em tal aspiração. $\mathrm{O}$ eminente $\mathrm{De}$ Crecchio, que é o mais auctorisado propugnador da opinião contraria, leva ao extremo os seus argumentos. Não se contentaria em substituir por aspecto a palavra de que lança mão o legislador italiano. Iria mais longe: «ogni persona ha dritto «a conservare la venustà dell'intiero suo corpo, ed «una grave scottatura che deformasse il dorso di una «donna, anche nelle parti che sogliono portarsi sempre «coverte, le avrà recato un danno che diminuisce la «venustà della sua persona.» E accrescenta que muitas mulheres tiram vantagem da perfeição do corpo (bailarinas, actrizes): «ora le gravi tracce di lesione che de«formassero il seno, le spalle, le braccia di tali persone, «a me pare che meritassero una considerazione, come al«tresi tutte le donne che, pure non appartenendo alle «categorie suddette, possono venir dannegiate e limitate «nella loro libertà di abbigliarsi, secondo il costume che «in alcuni casi esige vestimenta per cui le braccia, le «spalle e parte del petto rimangono denudate.»

(I) DE Cola Proto, o. c., p. 9I.-ZIINo (Prontuario scientificopratico di clinica forense, 1896, p. 3I2) prefere tambem "questa voce (aspetto) che è di larga compreensione, a quella di faccia, troppo restrittiva.»

(2) Lavori della commissione al Progetto del codice penale, parte II, 1878 , p. 137 .

(3) ANNibale AlPI, Sfregio e deformazione permanente quali conseguente' di lesioni personali, I896, p. I. 
Julgamos facil a resposta.

A razão da pena reservada ás lesões productoras de deformidade não vem apenas da necessidade de proteger a esthetica individual, é mais complexa, obedecendo a outras consideraç̃es que já deixámos apontadas no capitulo anterior, e que não concorrem quando o traumatismo se localisa em outro logar que não o rosto. Accresce que punir com a mesma pena uma deformidade do rosto e uma cicatri\% deformante do collo, ou uma deformidade do collo e uma cicatriz deformante situada, por exemplo, na região axillar, seria equiparar para a medida penal lesões desmedidamente diversas. E a obviar esse absurdo, sómente um meio se nos apresenta: voltarmos ás tarifas da legislação medieva. Ora, é o proprio De Crecchio que, com toda a razão se insurge contra a consagração legislativa de graus de deformidade, a particularisação de todas as consequencias estheticas das lesões corporaes. Quanto ao argumento de existir quem viva da formosura do corpo, não cremos que mereça uma refutação séria: imagine-se um codigo, em que se dissesse que maior pena está reservada ao delinquente que deforma o collo de uma bailarina!

O que nos parece é que a doutrina contraria parte de um presupposto falso: entende que o criterio civil da reparação do damno deve ser o mesmo criterio que preside ás disposições penaes. Num codigo civil comprehende-se que se dê apreço a algum dos argumentos que refutámos (I): num codigo penal, seria absurdo e ridiculo consagral-os.

(I) O codigo civil austriaco diz no art. 1326: «se do terimento resultar desfiguração, o offensor é obrigado a reparar o damno que della resultar, sobretudo quando a pessoa offendida pertencer ao sexo feminino.» $\mathrm{F}_{\mathrm{T}}$. N. GIORDANI, Il nuovo codice penale generale austriaco, 1852, I, p. $29 \mathrm{I}$. 
25.) - Resta firmar o que abrange a palavra rosto, que empregáinos ha pouco, e dizer o motivo porque preferimol-a a face, aspecto e semblante, que commummente se applicam ao mesmo objecto: a parte anterior da cabeça. Semblante significa mais propriamente o rosto considerado como expressão dos affectos ou paixões (I). Aspecto offerece margem a ampliações inconvenientes. Restaria a palavra face, que, exprimindo rigorosamente a maçan do rosto ou cada uma das partes lateraes da cara, desde os olhos até á maxilla inferior, se applica por extensão a todo elle. E' de temer, porém, que se tome essa palavra no restricto sentido que the emprestam os vocabularios (2) e a anatomia (3), excluindo-se de sua comprehensão o pavilhão da orelha, que tanto interessa á venustez das linhas physionomicas (3). Rosto, além de ter por si a consagração da nossa legislação primitiva, além de comprehender tanto a forma, os traços, como a expressão, - pode invocar em seu favor o que Zanardelli dizia da palavra italiana correspondente:-em sua accepção vulgar, parece que mais exactamente indica a parte anterior da cabeça, que da fronte vae á extremidade do mento e de uma á outra orelha, comprehendendo

(I) Roquette, Diccionario de synonymos.

(2) CANDido DE Figueiredo, Novo diccionario da lingua portugueza, diz que a face comprehende testa, olhos, nariz, maçans do rosto, labios e queixo. LAROUSSE, Dictionaire universel, t. VIII, dá-lhe a mesma comprehensão, no que concorda o Century Dictionary (... Lhe facial region or facies containing the eyes, nase and mouth, but not the ears). LE DENTU (Nouv. Dictionn. de méd. et chir. prat.) diz que a face é-«cette partie de la tête que limitent extérieurement la ligne d'implantation des cheveux, les oreilles et l'arc du maxillaire inférieur.» Hyrtu, Anat. Topographica, exclúe da face a fronte. PAUlex (Résumé d'anatomie, r 884, p. 27) dá, como limites extremos da face, em cima-a linha curva sinuosa que marca o limite inferior do craneo, em baixo-o plano obliquo que separa a cabeça do pescoço, e divıde-a em seis porções (ocular, olfactiva, buccal, auditiva, masseterina e parotidiana). Na medicina legal italiana, é corrente que a face está circumscripta por duas linhas que, partindo do ponto em que ordinariamente se inserem os cabellos, e, passando adeante das orelhas, ganham o bordo livre do maxillar inferior e se unem no mento (MADIA, o c., p. I75). 
os pavilhões, parte que maiormente importa á belleza e á dignidade humanas (I).

26.) - Na Italia, sob o dominio do codigo sardo, a medicina forense e a jurisprudencia discutiam a punibilidade das lesões deformantes do pavilhão da orelha. Uma sentença da Corte de Appellação de Messina, em I I de Novembro de I87I, cortara a questão pela negativa (2), fundando-se na occultabilidade da lesão. Caprara allude vagamente a uma sentença de I 887, em que se decretou a inapplicabilidade do artigo 538 do codigo sardo á hypothese semelhante (3). Em contrario, a Corte de Appellação de Catania pronunciou a sentença de I 3 de Dezembro de I 877 (4); e, neste ultimo sentido, já sob o dominio do codigo italiano, se manifestou a Cassação em 2 I de Março de I 89 I (5).

Na Republica Argentina, ha uma sentença de Rivarola, confirmada na superior instancia, em que se

(I) Diz, Vanguerve, Pratica judicial, 1842 , in novam justitice reformationem, $\mathrm{n}$. $156:$ : $\mathrm{E}$ a face se entende de todo 0 rosto da barba até os cabellos exclusivé, como tem BALD. e ANGEL. in d. L. Si quis in metallum: DUEÑ. dicta regul. 290. ANGEL. de maleficiis, verb. non facies, n. I. Additio ad BART. in L. cum in diversis, ff. religios. et sumpt. funer. Calepin. in verb. Facies.» Escreve LEITÃo, De inquisitionibus, quæst. III, n. I 24:- - «aciei autem nomine comprehendentur, frons, oculi, nasus, os, malaet mentum.»

(2) «La lesione al padiglione dell'orecchio nou costicuisce il deturpamento permanente della faccia previsto dall'art. 538 del Cod. Penale. Perchè la ferita produca deturpamento è indispensabile non solo la lesione delle forme, ma l'appariscenza di questa lesione ut vestibus non contengatur...» ZIINo, Compendio di medicina legale, II, I883, p. 78. PugliA, Manuale, cit., diz, a respeito dessa decisão, que ella não é acceitavel «perchè l'orecchıo è una delle parti che si osservano da chi guarda un volto di prospetto.»

(3) Lettera, no Giorn. de med. leg., I, p. I53.

14) «La deturpazione alla faccia può anche essere prodotta da una ferita all'orecchio détormando l'aspetto.» Silvio LESSONA, Elementi di diritto penale positivo, p. 152.

(5) «L'orecchio fa parte dei contorni del viso; e quindi la mancanza totale o parziale di esso turba l'estetica e l'armonia del viso medesimo e costituisce lo sfregio di esso." (Cassazione unica, IIJ, p. 933). L. BoRkI, o. c., p. 54. Da materia trata DE CAPiTANI, Sfregio e deformazione, na Cassa. zione unica, V. 1895 , p. $32 \mathrm{I}$. 
decidiu, que não constitue deformidade notavel a perda da terça parte do pavilhão da orelha. $\mathrm{Na}$ Hespanha parece prevalecer a opinião opposta (I), que, aliás, tem por si a longa tradicção dos velhos medico-legistas, desde Fortunato Fidelis e Zacchias (2).

Perante a doutrina que sustentamos, a duvida não é possivel.

27.) -Em artigo publicado na Revista MedicoLegal, da Bahia, o dr. Alexandre de Souza discute, perante a anatomia e a medicina forense, se os dentes, orgãos endo-oraes, fazem parte do rosto (3). A questão não dá margem a demorado exame.

E' incontestavel que, pela sua situação especial, os dentes exercem extraordinaria influencia sobre a esthetica da figura humana. Desvenda-os o mais leve descerrar dos labios. Pondera com felicidade o dr. Sousa que, a excluil-os da generalidade das partes que compoem o rosto, deveriam tambem ser excluidos os olhos: se áquelles antepoem-se os labios, aos ultimos antepoem-se as palpebras.

Não cremos, porém, (e diremos mais tarde o motivo) que a avulsão de dentes constitua deformidade, no sentido do art. 304 de nosso codigo.

28.) - A deformidade deve ser INDELEVEL ou PERMANENTE.

Quanto a este caracteristico das lesões deformantes nenhuma duvida se tem erguido. Alguns codigos expressamente consagram-n'o: o sardo, de i 859

(I) «Por no distinguir el código en su espresión general clases distintas de deformidad, comprende como tal para los efectos juridicos en el previstos, la fealdad visible resultante de una irregularidad física, permanente y definitiva.» Sentença do Tribunal Supremo, citada por R. Rivarola, Código penal, II, p. Iog.

(2) SORIANo, Ensaio, cit., p. 202, nota 2."

(3) Lesões dos dentes, na Revista medico-legal, II, p. I43. 
(deturpato permanentemente), o allemão (deformar permanentemente), o projecto do codigo austriaco, de 1874 (desfigurado para sempre), o codigo da India Ingleza (desfiguração permanente), o codigo italiano, o uruguayo e o projecto do codigo brasileiro, que usam do mesmo qualificativo. No silencio da lei, a jurisprudencia não hesita: apenas como exemplo, citaremos a sentença do Tribunal Supremo de Madrid, em que se comprehende como deformidade a fealdade visivel resultante de uma irregularidade physica permanente $e$ definitiva (1), outra do mesmo Tribunal que firma ser necessario que os effeitos da imperfeição tenham caracter permanente, para legitimar a applicação do art. 43 I $\S 3 .^{\circ}$ do codigo hespanhol vigente (2), e, afinal, a de um juiz de S. Paulo, que, desclassificando o crime do art. 304 (lesões graves) para o art. 303 do codigo de 1890 (lesões leves), se fundou nos dizeres do auto de sanidade, onde se fez certo que desappareceriam "as manchas dependentes do trabalho de reparação da pelle», uma vez terminado esse processo de reintegração (3).

Não nos foi possivel apprehender a razão a que obedeceu a Camara dos Deputados para aggravar a

(i) Rivarola, Cód. Pen., II, p. iog.

(2) Sentença de 18 de Novembro de 1893 , na Jurisprudencia criminal, LI, I 894, p. 33I : "considerando que el supuesto de la deformidad, si bien toda cicatriz en el rostro de una persona produce cierta imperfección en aquél, para que esta se convierta en verdadera deformidad, es preciso que lo ostensible de la buella y las condiciones de la misma desfiguren á la persona, y que sus efectos sean de caráiter permanente...

(3) Sentença do dr. Clementino de Castro, no processo contra Pasquina Montanari Vaz. Movida pelo ciume, a accusada, que exercia o mister de chapelleira, lançára, segundo o auto de corpo de delicto, «um liquido corrosivo (acido concentrado)" á face da rival, moça de 19 annos. Os primeiros peritos encontraram «manchas pardas extensas produzidas por queimaduras... occupando as regiŏes malares e maxillar superior de cada lado, frontal, nasal e ante-braço direito»; notaram ainda que «o aspecto do rosto era disforme e que as palpebras estavam muito inflammadas»; e affirmaram existir «a deformidade do rosto, produzida por manchas e cicatrizes indeleveis.» Os segundos peritos, vinte e tres dias depois, negaram a deformidade. 
penalidade das lesões que deixam cicatriz temporaria no rosto: os Annaes são mudos sobre o ponto. E' eviderte o absurdo da innovação, que, segundo parece, não encontra precedente na legislação dos povos cultos. Já deixamos dicto que deante da letra núa do projecto, a cicatriz permanente, desde que não seja cleformante, não determina a gravidade do delicto: determina-a uma cicatriz transitoria! Desde que pune com maior pena as consequencias temporarias das lesđes, o legislador, para ser coherente, deveria tambem capitular como graves as deformidades de pouca duração, visto que deformidade não é synonymo de cicatriz, e, no entretanto; não o faz. Si qualquer cicatriz temporaria acarreta o augmento da penalidade, porque uma ecchymose ou uma inflammacão transitorias não a produzem?

29.)-Cumpre que à indelebilidade seja certa, e não simplesmente provavel. (I). A proposito, Carrara, lembrando que o criterio citado repousa sobre a exactidão do prognostico medico, observa que é necessario não esquecer jamais as forças inexhauriveis da natureza, que zombam muitas vezes das affirmações dogmaticas de peritos levianos.

Para fugir a criticas dessa natureza, o medicolegista, salvo casos excepcionaes, não deve proferir o seu parecer definitivo, senão depois de completar-se a evolução do processo morbido e de terminar, por inteiro a cicatrisação consequerıte ao ferimento (2). D'ahi,

(1) Cola PRoto, Il reato di lesione personale, p. 91.-No entretanto, o Tribunal de Justiça de S. Paulo, numa causa celebre, julgou applicavel o art. 304 do Cod. Pen. ao agente de uma lesão que, segundo os medicos-legistas, PODERIA produzir deformidade!.

(2) DE CRECCHIo (Giorn., cit., p. 4) ensina: "Dal punto di vista medico-legale, mi pare che non si debba considerare come sfregio il taglio o qualsiasi altra lesione mentre è in atto, ma soltanto quando è guarita e lascia una cicatrice, giacchè il carattere di permanenza che il legislatore vuole 
a imprescindivel decretação do exame de sanidade, que é a contra-prova do primeiro exame e a verifica ção do estado definitivo das lesões descriptas e dos resultados previstos no auto de corpo de delicto.

Parece-nos que os unicos casos, em que o perito pode julgar-se desde logo auctorisado a pronunciar-se com certeza, são os de perda muito consideravel de substancia e os de contemporaneidade ou coexistencia de deformidade e de mutilação grave. Quando esses effeitos se produzem, o afeamento é necessario e constante.

30.) - Não será inutil pôr em relevo alguns factos relativos á evolução das cicatrizes.

Quotidianamente observa-se que navi materni situados no mento e na parte superior da fronte de creanças, com o decorrer do tempo, descem para o pescoço ou se occultam sob os cabellos: devem-se esses effeitos á mobilidade natural da pelle, durante, o desenvolvimento. Em egualdade de circumstancias, o mesmo dá-se com as cicatrizes livres que, situaclas junto á linha de implantação dos cabellos ou ao bordo do maxillar inferior, não interessam os tecidos sub-cutaneos. E' uma possibilidade que peritos e magistrados devem levar em conta, desde que apenas são deformatorias as cicatrizes permanentes-do rosto.

Outra questão que sobremaneira importa á solução do problema, é a da indelebilidade das cicatrizes. Nem todas ellas são persistentemente perceptiveis a olhos nús (I): trata-se não de um desapparecimento

nello sfregio non può sempre giudicarsi mentre la lesione è in cura e fa il suo decorso, ma soltanto allora che le cure ed il decorso della lesione sieno esauriti.»

(I) «In teoria, ogni cicatrice è visibile e persistente: anco le cicatrice risultanti da strumenti affilatissimi e taglienti e quelle delle mignatte possono 
real, mas de um desapparecimento apparente. Neste ponto, como em quasi todos os outros de medicina legal, não é possivel formular preceitos inflexiveis: tudo depende das proteiformes circumstancias de cada um dos casos sujeitos a exame. No entretanto, recordaremos que as cicatrizes superficiaes se vão delindo progressivamente, se tornam, pouco a pouco, menos distinctas e muitas vezes se cancellam (I). Nunca desapparecem as cicatrizes consequentes a perdas de substancia, sobretudo quando o agente vulnerante é um caustico solido ou liquido (2). Os ferimentos que se curam por suppuração e por granulações deixam geralmente cicatrizes, que persistem por tempo indefinido (3).

31.) - Para caracterisar o delicto que estudamos, não basta que a lesão esthetica do rosto seja permanente: \& necessario que seja APPARENTE, VISIVEL, PERCEPTIVEL ao primeiro olhar.

Prescrevem-n'o expressamente varias legislações antigas, como os direitos suecos e frisão, e alguns codigos modernos, como o hungaro (4), o de Thurgovia e o de Grisons. Consagra-o a jurisprudencia: vejamse, por exemplo, os arestos do Tribunal Supremo da

essere verificate dopo parecchi anni, giovandosi all'uopo di una lente d'ingrandimento." A medicina judiciaria dispõe de variados meios para tornar visi. veis as menores cicatrizes. Veja-se, a proposito de cicatrizes de sanguesugas, uma communicação de DE CASTRo, nos Annales d'hygiène et médecine légale, 1887 , I, p. 48 .

(I) CARLO WEIL, Le cicatrice sotto il rapporto medico-legale, no Trattato de Maschka, I, p. 483. S. LAuRA, Trattato di medicina legale, 18 74, p. 203.

(2) L.Aura, o. e l. c.-J. I. CAsper, Traité pratique de médecine légale, trad. Baillère, II, I862, p. 8I.

(3) A. S. TAYlor, Traité de médecine légale, trad. Coutagne, $188 \mathrm{I}$, p. 340. MALle, Annales d'hygiène et médecine légale, I840, I, p. 422.

(4) Institución de Justicia de Hungria, cit. por I. MAESTRE, na Revista general de legislación, XCIV, p. 544. 
Hespanha, que anteriormente citámos (r), a decisão da Cassação italiana em 20 de Abril de I89 I (2) e uma sentença da Camara de Appellações de Buenos-Ayres, que julgou não constituir deformidade uma cicatriz imperceptivel no nariz (3). E esse é o pensamento da grande maioria dos medico-legistas e dos escriptores de direito penal.

Notaremos, porém, que o requesito da visibilidade se refere tanto ás cicatrizes deformatorias, como aos seus effeitos sobre a esthetica do rosto. Um exemplo dará maior nitidez a essa consideração: pode ser imperceptivel a cicatriz consequente a um traumatismo, que interesse um nervo importante, produzindo a paresia ou paralysia de um ou varios grupos musculares que exerçam influencia sobre a funcção mimica.

Certos ferimentos, especialmente os que tem por séde a região paratodiana, affectando o nervo facial, determinam uma paralysia transitoria ou permanente dos musculos da face (4), o que constitue, sem duvida, uma

(I) Sentença de 18 de Novembro de 1893: "para que tal deformidad exista es absolutamente necesario que lo ostensible de la huella y las condiciones de la misma desfiguren á la persona lesionada» (Jur. Crim., LI, p. 331)-Sentença de 27 de Dezembro de 1893: "La deformidad existe cuando queda permanente y visible un defecto fisico que altera la forma natural de la cabeza...» (Jur. Crim., LI, p. 477). -Sentença de I. de Abril de 1896 (Jur. Crim., LVI, p. 460)-Sentença citada por R. Rivarola (Exposición y critica del cod. pen. arg., II, p. Iog), na qual se firma constituir deformidade "la fealdad visible resultante de una irregularidad fisica, permanente y definitiva.»

(2) «La deformazione del viso significa una alterazione siffatta. da renderlo in guisa che produca, in chi lo guarda anche superficialmente, un senso di disgusto...» (Cassazione Unica, II, p. 330). E' certo que outra sentença do mesmo tribunal assevera «costituire sfregio qualunque segno permanente lasciato dalla lesione sul viso, anche quando il segno sia impercettibile. ." Mas, segundo observa BORRI (Les. traum., p. 53) não se faz mister muita agudeza, para verificar que tal proposição está em pleno e absoluto desaccordo com o espirito do codigo italiano.

(3) Malagarriga, Cod. pen. arg., p. 150.

(4) Borri, Les. traum., p. 53 e 405. Como exemplo, podemos apontar a incompleta occlusão das palpebras (lagophtalmia). 
deformidade grave. No entretanto, a cicatriz será algumas vezes insignificante. Mas as consequencias da lesão traumatica estarão perfeitamente visiveis, e será inepcia negar a existencia da deformidade.

32.)--Prende-se ao ponto de que tratamos uma observação interessantissima de De Crecchio, observação que demonstra que uma mesma cicatriz, num mesmo ponto do rosto, será deformatoria num caso e não o será em outro.

Um velho camponez, cujas faces, devido á ausencia de dentes, formavam fossas abaixo das maçans do rosto, foi ferido em uma rixa. A bala de revolver entrou pela face direita, e, esflorando o angulo labial esquerdo, sahiu pela bocca, que o offendido tinha aberta, por estar gritando no momento do crime. O projectil penetrou no ponto em que mais profunda era a depressão da face. O ferido, cuidadosamente medicado, observou com escrupulo o preceituario medico; e, terminada a cicatrização, não se verificou a deformidade, nenhuma differença havia entre os dous lados do rosto e os dous perfis, e a cicatriz se occultára na depressão da face direita, onde casualmente fôra ter o projectil (I).

As cicatrizes lineares ficam frequentemente occultas entre as rugas que sulcam a face dos velhos. Outras vezes, correndo parallelamente ás rugas, com ellas se confundem. Identico effeito podem produzir cicatrizes de exigua extensão, offendendo uma epiderme rugosa e curtida pelo sol, como a dos homens de campo. Em qualquer dessas hypotheses não se poderá fallar de deformidade apparente.

33.)--O que acabamos de expôr servirá de transiç̧ão ao estudo do ultimo caracteristico das lesões deformatorias-a IRREPARABILIDADE.

(I) Giornale, cit., I, p. 108. 
Como reparavel capitulamos a deformidade propriamente curavel e a deformidade susceptivel de dissimulação. A cura, é uma verdadeira restitutio ad integrum, sob o ponto de vista esthetico; a dissimulação occulta, mas não remove o defeito subsistente.

Parecerá ao primeiro exame que a dissimulação devia ter sido considerada ao tratarmos da visibilidade dos traumatismos deformantes. Julgamos, porém, mais acertado distinguir a dissimulação, por assim dizer, natural (como no caso do velho de De Crecchio), da dissimulação, por assim dizer, voluntaria ou provocada: depara-se-nos grande a differença entre $c$ facto de uma cicatriz occultar-se casualmente entre as margens de uma ruga, e o facto do offendido deixar crescer a barba para subtrahir á contemplação alheia a anomalia que o fere. E levaram-nos ainda a essa convicção o accordo que na doutrina se encontra, negandose geralmente a existencia da deformidade no primeiro caso ( $\mathrm{I}$ ), e as divergencias profundas que desunem os scientistas na apreciação do segundo.

34.) - Ha deformidades perfeitamente curaveis. Dous escriptores contemporaneos recommendam que não se recorra á intervenção cirurgica immediata para operar a reparação auto ou heteroplastica dos ferimentos da face: a natureza é capaz de tăo generosos esforços, a pelle do rosto presta-se a tão maravilhosas reparações expontaneas, graças á ampla irroração sanguinea da região, que se deve primeiramente esperar de uma e de outra tudo quanto podem dar (2). E, reforçando o conselho, citam factos inteiramente demonstrativos. Quando a reparação expontanea, evoluida sob a vi-

(1) Contra-Von LiszT, Trat. de dir. pen. all., trad. José Hygino, 1899, II, p. 34, que entende ser applicavel o $\$ 224$ do codigo allemão, quando mesmo "o fato possa encobrir a deformidade».

(2) E. FORGUE e PAUL RÉClus, Traité de thérapentique chirurgicale, II, I 898 , p. 348 . 
gilancia do medico, tenha concluido a sua obra, a restauração autoplastica virá completar, e, sendo necessario, rectificar os resultados obtidos. A restauração expontanea (concluem os tractadistas que citámos) offerece apenas um perigo-as desviações inodulares; e, por isso, faz-se mister que o trabalho cicatricial seja dirigido e mesmo corrigido.

Borri, no exhaustivo trabalho sobre lesões traumaticas (I) e Weil, em seu magnifico artigo inserto no tractado de Maschka, ponderam que o perito deve sempre verificar se a deformidade é devida á inepcia do tratamento, e se pode ser removida por qualquer operação: muitas vezes a lesão á esthetica desapparece, supprimindo as bridas cicatriciaes salientes ou rasgando a cicatriz e applicando uma boa sutura (2).

Seria transpôr os limites desta monographia, aprofundar as ligeiras noções que ficam expostas sobre a curabilidade das lesões deformatorias. No entretanto, merecem mais demorado exame as lesões dos dentes, do globo ocular e do nariz.

35.) - A avulsão de um ou mais dentes incisivos constitue deformidade? Respondem affirmativamente Ed. Doll (3), Tomás Maestre, Carlos Weil (quando se trata da fractura de muitos incisivos sãos de uma rapariga) (4), Secondo Laura, embora entenda

(I) Les. traum., p. 405 .

(2) Tratt., I, p. 479: "Applicando male le suture, scegliendo un cattivo materiale da sutura (aghi grossi e fili molto spessi), lasciando le suture troppo a lungo in sito, trattando male la ferita (con che non s'impedisce la suppurazione, che può essere facilmente evitata segnatamente quando trattasi di ferite della faccia), le cicatrici possono ampliarsi e divenire ineguali. Specialmente quando trattasi di ferite delle palpebre e delle labbra, può prodursi una grave deformità per ineguale livello dei loro margini allorchè la sutura non venga fatta accuratamente.»

(3) Der Verlust von Zähnen in gerichtsärtlicher Beziehung Oesterr. Zeitschr. f. pr. Heilkunde Herausg. v. d. Doctoren-Colleg. der medicin. Facultät in Wien, IV, 5 . I, p. 290 .

(4) Produzione delle lesioni violente meccaniche, em MAschKA, Tratt., 
que a opinião contraria é sustentavel «non senza argumento di ragione» (1), von Liszt (2), Lombroso (3), Lorenzo Borri, que, no entretanto, não deixa bem claro o seu pensamento (4), e, no Brasil, Soriano de Sousa (5), Alexandre de Sousa (6) e Sousa Lima (7), que, deante do Codigo Penal vigente, abraça a doutrina adversa (8).

No mesmo sentido encontram se varios julgados estrangeiros e patrios: assim, alguns arestos da Corte Suprema da Hespanha, ordenando a applicação do art. 43 I $\S 3 .^{\circ}$ do codigo no caso de avulsão de dois incisivos (9), uma sentença do juiz de direito de Pomba (Minas Geraes), que pronunciou como incurso no art. 304 do codigo vigente o auctor da fractura de um dente, sendo a victima uma mulher do povo e casada (IO).

(I) Tratt. di medic. leg., I 874 , p. I 74.

(2) Tratado de direito penal allemãa, II, p. 34.

(3) Lezzoni di medicina legale, 1886. O egregio professor de Turim parece, no emtanto, admittir que, sendo reparavel, a perda de dentes não constitue deformidade.

(4) «...Certe fratture trasversali del mascellare superiore, che ne interessino il processo alveolare, possono causare la contemporanea caduta di varii denti, per modo che ne risulti un danno e nella pronunzia delle parole e nella funzione masticatoria assai notevole; danno che eventualmente può non venire riparato da nessuna sorta cli apparecchi di protesi. Però, anche in questo caso, non parmi possa ammettersi che il danno rientri nei termini di una invalidità, pur di tenue grado; un'indemnità sarà, in ipotesi, ripetibile, unicamente in base a considerazione di ordine differenti (deturpamento, ecc.)»

(5) Ensaio medico-legal, p. 205.

(6) Lesões dos dentes, na Rev. med. leg., da Babia, II, pag. 142 e seg.

(7) Traumatologia forense, na Revista dos cursos praticos e theoricos da Faculdade do Rio de Janeiro, 1887, p. I37.

(8) Consulta sobre o processo do dr. Edgard Prado, nas Razões dos querellados.

(9) Rivarola, Cod. penal, II, pag. I09-A outra sentença (29 de Outubro de I 886) é transcripta por Tomás MAEstre (Rev. de legisl., cit., XCIV, p. 533).

(10) Forum (Bello-Horisonte), VII, p. 637. Da sentença não consta se o dente era incisivo, canino, premolar ou molar. $O$ juiz basea-se nas palavras de Soriano (que aliás se refere á avulsão e fractura de varios dentes), e no sentido grammatical da palavra deformidade. Releva notar que esse julgado reformou o despacho do juiz substituto, que, muito correctanente, applicára o art. 303 (ferimentos leves). 
Mas a maioria dos medico-legistas contemporaneos segue diverso rumo: entre todos avultam Ziino, Hofmann, Schulmacher (I), e, em nosso paiz, Nina Rodrigues. A jurisprudencia argentina adopta o mesmo pensar (2). e ha julgados brasileiros que the seguem o exemplo (3).

Referindo-se á avulsão de dentes, Ziino ensina positivamente que de deformidade «non v'è neanco a "parlarne, potendo esistere facce bellissime da muovere «tutt'altro che il sorriso con la contemporanea man«canza d'uno o di due denti, fossero anche gli inci«sivi» (4), e, em diverso trabalho, accrescenta: «nè «meno sciocca è la pretesa di coloro i quali (per amore «di difesa della parte civile che paga, e non per con«vencimento) sostengono che la caduta violenta di uno «o due denti sfigure siffatamente l'aspetto, da aversi la «deturpazione permanente della faccia» (5). Affigura-senos inteiramente justo o fundamento adoptado pelo auctorisado escriptor, quando se trata da perda de um ou dois dentes. São tão communs os defeitos dessa natureza, devidos a causas não traumaticas, que não podemos equiparal-os ás lesões verdadeiramente deformantes. Mas é incontestavel que sobre a formosura da face influe a perda de muitos dentes incisivos e caninos. A integridade, não é, segundo os escholasticos, um dos

(1) Segundo WeIl (Tratt. de MaschKa, I, p. 290).

(2) Acuerdos y sentencias de la Suprema Corte de Justicia de la Provincia de Buenos Aires, 2." série, VII, p. 4.4\%. Tratava-se, na bypothese, da avulsão de dous incisivos.

(3) Sentença do juiz da I.' vara de S. Paulo, dr. Thomaz Alves, no processo-crime contra Anesio Azamb!ja. Dizia o auto de corpo de delicto: - «com a pancada houve arrancamento de quatro dentes, sendo um canino e "dois incisivos inferiores esquerdos; um dos incisivos superiores foi tambem "quebrado; houve tambem fractura de uma dentadura postiça superior.» O exame de sanidade fez certo que «das offensas descriptas no auto de corpo de delicto.. resultou sómente deformidade remediavel e em parte já remediada por dentadura postiça, quanto aos dentes naturaes...»

(4) Comp. de med. leg., II, I883, p. 78.

(5) Prontuario scientifico-pratico di clinica forense, p. 324. 
elementos substanciaes do bello? Nos ceus e na terra, na luz e no som, na flora, na fauna, em nossa propria forma que é a belleza senão «l'éblouissement immédiat, «et d'emblée vainqueur, de l'harmonie (I)?»

Nina Rodrigues entende que a perda dos dentes não é deformidade, tomando se esta palavra para significar o deszio do typo especifico humano, visto como, tanto no inicio como no fim da vida, em pleno estado hygido e physiologico, a ausencia de dentes é um facto commum; e ninguem dirá que a creança, em que não se realisou a erupção dentaria, e o velho, que. a involução senil desdentou, hajam por isso perdido o typo de sua especie. Tomando-se deformidade como synonymo de fealdade, desvio de um determinado typo de belleza, pensa o professor bahiano "que só se pode "admittir a existencia de deformidade, quando concor«rem as circumstancias da perda de diversos incisivos, «difficilmente reparavel, em uma senhora e senhora «joven» (2).

Entendemos, com Hofmann, que é relativamente facil sanar o defeito physico resultante da fractura ou da luxação dos dentes (3).

Trata-se de uma luxação completa? A reimplantação e a transplantação, conforme o caso concreto, extinguem o mal.

Trata-se de uma fractura? Quando a fractura é simples, a reparação não é difficil; e, limitando-se a perda de substancia á terça parte da corôa, sobretudo quando o offendido é uma creança, podese esperar que o dente desça por si mesmo ao nivel dos outros, auxiliado por tracções artificiaes. Quando a fractura é

(I) Maurice Griveau, L'esthétique de la nature, na Revue Encyclopédique, 1898 , p. 186.

(2) Rev. med. leg., da Bahia, II, p. I69 e seg.

(3) WedL, Iraité de pathologie dentaire, $189^{2}$, cita quinze casos de consolidação depois de fracturas longitudinaes ou obliquas. 
completa, um pedaço de porcellana preso a um pivot fixado no canal radicular, substitue o pedaço da corôa destruida; e, quando esta se acha completamente perdida, colloca-se um dente a pivot (I). Emfim, quando se trata de uma fractura comminutiva, a greffe ou a prothese dentaria fornecem a reparação desejada (2).

E' certo que os apparelhos protheticos não eliminam todas as consequencias graves das lesões dentarias (phonação defeituosa, etc.); mas a reparação esthetica é integral, e neste trabalho apenas consideramos a consequencia esthetica das lesões. Digamos de passagem que não é comparavel a substituição artificial dos dentes perdidos á adaptação de um pé, de uma mão ou de um olho artificiaes: a primeira ao envez da segunda, restitue á victima a forma $e$ o poder funccional dos orgãos substituidos. A reparação é, por assim dizer, completa (3). No entretanto, como as circumstancias que formam o ambiente de cada caso particular, variam infinitamente, o perito deve mencionar minuciosamente a especie e o numero de dentes lesados, o seu grau provavel de resistencia, o estado anterior da dentadura da victima (integridade, anomalias, etc.) e se a reparação é impossivel.

36.)-O que deixámos dicto sobre as lesões dentarias applica-se em grande parte aos traumatismos dos olhos e de seus annexos. A deformidade resultante da perda de substancia das palpebras encontra muitas vezes nas operações blepharoplasticas remedio mais ou menos efficaz. A prothese corrige

(1) Consulte-se o copioso trabalho de OsCAR AmooËo, L'art dentaire en médecine légale, I898, p. 3 I 3 e seg. e $38 \mathrm{r}$ e seg.

(2) Lombroso, Lez. di med. leg., p. 298.

(3) "Nella maggior parte dei casi, il danno del corpo causato dalla perdita di uno o più denti, si può materialmente compensare con opportuni apparecchi e di ciò, in tesi di danno pcrsonale da causa fortuita, va tenuto, come accennamo varie volte, il massimo conto.» L. BORRI, o. c., p. 409. 
a desfiguração consequente á ablação ou atrophia dos olhos. A's vezes, porém, a cicatrisação viciosa, o estreitamento do cul-de-sac conjunctival, etc., tornam difficilmente toleravel o uso da peça artificial, ou immobilisam-n'a, de forma que a deformidade subsiste ( $\mathrm{r}$ ). O ectropion e o entropion cicatriciaes são muitas vezes removidos pela cirurgia (2).

A jurisprudencia argentina segue tendencia contraria á que adoptámos: julga que «la circunstancia «de que el defecto pueda disimularse por medios arti"ficiales, no quiere decir que desaparezca» (3). E' claro porém, que, deante do nosso codigo penal, embora tenha desapparecido o damno esthetico, a ablação do globo ocular é punida como ferimento grave pelo art. 304, que comprehende, além da deformidade, a mutilação ou amputação e a privação permanente do uso de um orgam ou membro (4).

37.)-A proposito das lesões do nariz, foi ha algum tempo, submettida á nossa apreciação a seguinte consulta: «a perda total do nariz é uma deformidade irreparavel»? Respondemos affirmativamente: nenhum dos varios processos de rhinoplastia total consegue remover a fealdade resultante da perda do orgam. Dizem-n'o Letiévaut (congresso de Paris, de i 878), Dolbeau, Gaujot, Larrey (Sociedade de Cirurgia de França, 'discussão de I 874) (5).

(1) S. BAUDRY, Etude médico-légale sur les traumatismes de l'ail et de ses annexes, 1895, p. 137.-GRANDCLÉMENT, 'Les blessures de l'cil au double point de vue des expertises judiciaires et de la pratique médicale, I888.

(2) HASner, Lesione violente dell'occhio, em MASchKa, Tratt., I, p. 4I 2-4I3.-Forgue e RÉclUs, O. c., II, p. 253.

(3) Malagarriga, Cód. pen., p. I 49. No mesmo sentido, Von Liszt, o. e l. c.

(4) Vejam-se tambem uma sentença no Fóro italiano, I896, II, p. 4I7, e Lollins, La perdita di un occhio è sfregio, è deformazione, o invece perdita dell'uso di un organo? 1897.

(5) Não devemos esquecer o que, sobre os ferimentos do nariz, ensina Carlos WeIL, tantas vezes citado neste trabalho: "Tratti recisi del naso sovente cicatrizzano bene. BÉRENGER.FERAND (Gaz. des hópit. 1870) raccolsi 
Note-se que, se tratando de mutilação por um golpe de instrumento cortante, é susceptivel de exito a reunião immediata da parte destacada. O exito é muito duvidoso quando o ferimento é lacero-inciso (dentadas, etc.) (I).

38.) - Um individuo do sexo masculino apresenta uma cicatriz deformatoria em região provida de abundante systema piloso: no mento, por exemplo. Deixando crescer a barba ou conservando-a crescida, dissimula a cicatriz. E' applicavel o art. 304 do Codigo Penal?

Entendemos que a negativa se impõe, em que peze á auctoridade dos que impugnam a solução proposta (2) e ao grande numero de sentenças que a desprezam (3).

Se para cimentar uma opinião recorressemos apenas ao renome dos que a sustentam, opporiamos á

dalla letteratura 65 casi di questa specie (fra i quali 14 di scontinuità totale), che guarirono bene. In uno il naso reciso era stato rimesso in sito con sutura dopo cinque ore. MAlfatti (Wien. medizin. Wochenschr., 72) e BURCKHARDT (Inaugur. Dissertat., Berlin, 1872) hanno riferito casi analoghi. Circa le fratture delle ossa nasali è a rilevare, che dalla specie della deformità che resta si però deśumere come agi il trauma. Se questo colpì il dorso del naso, si rinverrà una depressione analoga a quelle deformità cosi frequenti che sono prodotte da osteiti sifilitiche. Con un trattamento adequato, si può in molti casi evitare la produzione di deformità permanenti.» (MASchKa, Tratt., I, p. 289).

(I) A proposito de ferimentos das azas do nariz, escreve ZinNo Comp., II, p. 91 : "Un procuratore legale venuto a diverbio con un giovanotto e da questo acremente provocato, con un morso gli strappara grande porzione della prima nasale sinistra. Fatta immediatamente la suttura, non fui fortunato tanto da vedere l'incollamento; eseguita pertanto una operanzioncella di rinoplastica in secondo tempo, il naso. s'è rimesso così bene da non lasciare deturpamento, e il P. anche oggi mena attorno la sua solida e lineare cicatrice, senza che gli si miri rotta l'armonia estetica del viso.»

(2) Borri, Les. traum., p. 56-Zinno, Clinica forense, p. $3 \mathrm{I}_{3}$, e Compendio, II, p. 78-Cola PRoto, Il reato di lesione personale, p. 89AnNibale AlPI, Sfregio e deformazione permanente, p. 5-Pincherli, Il codice penale italiano annotato, 1890, p. 524 .

(3) Côrte de Cassação de Palermo, em 30 Janeiro I 868 (Leggee, IX, I869, p. 82) e 3 Novembro 1877 (Foro italiano, II, col. 68); Côrte de appellação de Catanzaro em i 7 Abril 1883 (Riv. penale, XVIII, p. 576, n. 4). 
merecida auctoridade dos adversarios a auctoridade indiscutida de Hofmann (I) e Lombroso (2) no estrangeiro, e de Nina Rodrigues (3) e Sousa Lima (4) em nosso paiz, e accrescentariamos que na jurisprudencia patria e na de outros povos a nossa doutrina tem suscitado sympathias (5).

Hesitámos longamente entre as duas opiniōes Parecia-nos a principio que Ziino tinha razão, ao dizer pittorescamente que seria iniquo estabelecer, em prejuizo do offendido, «la perenne servitù di non potersi «radere la barba», e que «allevare o non la barba è nel "pieno arbitrio di chi soffre l'onta d'un marchio stam«patogli sul volto da un malfattore, ma non può il «leso essere costretto a scansare il rasojo per beneficare, «con un nuovo sacrifizio, il proprio offensore.» Julgavamos tambem que havia uma parte de verdade nestas considerações da Cassação de Palermo: «La cir"constanza di essere il deturpamento ricoperto dalla «barba non può cambiare la natura e l'essenza del «reato, che non deve assumere il carattere e la qua«lità da un elemento contingibile, eventuale, non vale«vole a cancellare l'essere proprio per sì della ferita, la «quali non può dirsi che non sia deturpante il volto, «perchè per una causa accidentale, non sempre colpisca "gli sguardi del pubblico, siccome non perderebbe it ca"rattere criminoso tal ferita, perchè quegli che patì lo «sfregio cammina o con la faccia coberta da qualsiasi

(I) Trat. de med. leg., I, p. 390.

(2) Lez. di med. leg., 303.

(3) Rev. med. leg., cit., p. I72.

(4) Consulta sobre o processo do dr. Edgard Prado.

(5) Tal foi o pensamento que presidiu á sentença da Côrte de appellação de Messina (I I de Novembro de r87 I), embora mal applicasse a doutrina á hypothese julgada. Tratando-se da perda do pavilhão da orelha, decidiu-se que, deixando crescer o cabello, o offendido podia dissimular a deformidade resultante daquella mutilação. Do mesmo parecer são HoFmann (Tratado, I, p. $5 \mathrm{I} 6$ ) e a jurisprudencia austriaca. 
«arnese, o con l'imbratto di empiastri» (1). Lembravamo-nos egualmente de que, se um individuo dissimulasse com oculos escuros uma deformidade das palpebras, nem por isso a lesão deixaria de ser grave. E ponderavamos, emfim, que existem profissões (sacerdotes catholicos, actores, etc.), que exigem de quem as exerce a tonsura da barba; e que os offendidos pertencentes a taes classes não podiam ficar sob a pressão deste dilemma: ou deixar apparente o gilvaz, ou renunciar á profissão.

Mas um demorado exame da questão convenceunos de que todos esses argumentos encontram refutação e resposta.

A Zino, diremos que deve o offendido procurar o remedio para a lesão recebida: assim como diminue-se a pena do homicida, quando a morte podia ser evitada por um conveniente curativo medico e não o foi, assim tambem a consequencia reparavel de um traumatismo que o offendido, podendo reparar, com um insignificante sacrificio, não repara, não pode ser levada á conta do offensor. Diremos outrosim que o melhor juiz da deformidade soffrida é a propria victima: se esta, furtando-se a um pequenino sacrificio, conserva apparente o gilvaz, fal-o naturalmente porque nenhum damno the advem do signal, fal-o porque julga que a lesão não the fere a regularidade dos traços. Occorre ainda que a deformidade e a reparabilidade são questões inteiramente de facto: quando a profissão do offendido tornar indissimulavel a lesão, o perito consignará tal circumstancia em seu parecer, e o juiz applicará a pena devida. Não procede o argumento aventado na sentença da Côtte de Palermo: o uso de arnese e de empiastri, por si só, quebra a harmonia dos

(I) Annibale AxpI, Sfregio e deformazione, p. 6. 
traços, substitue, na maioria dos casos, uma fealdade por outra. Mas ninguem dirá que a barba crescida afeie o rosto de um homem. Considerámos finalmente que, quando a deformidade é relevante, quando as cicatrizes desfiguram, mercê das condições de sua extensão e outras particularidades, a barba não as occulta, porque o systema piloso não se desenvolve no tecido cicatricial. Só muito raramente, portanto, a barba poderá occultar uma verdadeira desfiguração.

Nina Rodrigues escreve: "parece-nos que o di«reito á integridade do organismo. está sufficiente«mente garantido nos diversos itens da gravidade que «acarretam para as lesões pessoaes as suas consequen«cias legaes, e que seria excessivo rigor exigir que a «aggravante que resultaria da deformidade ou fealdade «apparente seja imposta, ainda quando esta fealdade «possa ser reparada ou disfarçada» (I).

Segundo Sousa Lima, «a caracterisação medico«legal da deformidade. não pode. sem clamorosa «injustiça, abranger os effeitos minimos daquelle acci«dente traumatico, entre os quaes se devem incluir as «cicatrizes do rosto, sobretudo em homem, e mais par«ticularmente ainda. em região, de ordinario, provida «de pellos, graças aos quaes podem ellas ficar occultas «ou pelo menos muito disfarçadas» (2).

E, emfim, Hofmann ensina: «de todos modos, no «deberán contarse, en esta categoria (deformidades), los «defectos fáciles de occultar» (3).

39.)-Da minuciosa analyse que até agora fizemos, resalta, em seus lineamentos caracteristicos, a figura da deformidade nas lesões pessoaes. São claros

(I) Rev. med. leg., cit., p. I72.

(2) Consulta, cit.

(3) Tratado, I, 390. 
os traços que a tornam inconfundivel com a mutilação, a amputação, a privação do uso de orgão ou membro, figuras delictuosas a que tambem se refere o art. 304 do codigo vigente. Existem lesões, como a mutilação do nariz, que duas vezes incorrem na sancção penal, ou, melhor, duas vezes offendem o preceito da lei. Mas nem por isso as duas figuras delictuosas se confundem: ha mutilaç̃os que não constituem deformidade, e vice-versa.

Em synthese, se nos fosse permittido esquecer que omnis definitio periculosa est, concluiriamos:

—é deformatoria a lesão pessoal que afeia ostensivamente o rosto humano, de modo permanente e irreparavel. 